www.jmscr.igmpublication.org

Impact Factor (SJIF): 6.379

Index Copernicus Value: 71.58

ISSN (e)-2347-176x ISSN (p) 2455-0450

crossref DOI: _https://dx.doi.org/10.18535/jmscr/v6i5.27

Journal Of Medical Science And Clinical Research

\title{
Open reduction and internal fixation of talar fractures using various approaches and its outcome: A case series study
}

Authors

*A.Sudharsan, E.Siva

Department of Orthopaedics, Thanjavur Medical College Hospital, Thanjavur, Tamilnadu, India

\begin{abstract}
Introduction: Talus fractures are common in injuries of high-energy mechanisms and also with other musculoskeletal injuries and systemic trauma. Treating talus fracture in the multiple injured patient is a challenge. Varied injury patterns of talus have brought in controversies and various approaches for the same type of injury.

Aim: A study to analyse various approaches and its outcome in open reduction and internal fixation of talar fracture.

Materials \& Methods: Seventeen patients were analysed in our study during the period of august 2014 to September 2016 with inclusion indication of simple and compound fracture of talar body and talar neck upto grade II compound injury with good general condition. All patients were reviewed at periodic intervals clinically with AOFAS scoring and radiologically with $X$-rays till union achieved.

Results: Among seventeen patients eight cases anteromedial, four cases combined anteromedial and posterolateral and five cases combined anteromedial and anterolateral approaches were performed for cannulated cancelous screws fixation. The mean AOFAS was 58.6 and was improved from preoperative score.

Conclusion: This study analysed various approaches performed in talar fractures to visualize talar neck and talar body and combined anteromedial and anterolateral approach found to be helped for better visualization of talar neck and talar body for good fixation.

Keywords: talar neck, talar body, approaches, cannulatedcancelous screw, internal fixation.
\end{abstract}

\section{Introduction}

Although talar injuries are unusual, they usually occur in high velocity road traffic accidents and fall from height. Varied patterns of injuries to talus have brought in controversies and various methods of treatment for the same type of injury. The role of the talus in lower extremity function, the complexity of the anatomy, and the different fracture patterns often complicate management of talar fractures and often frustrate orthopaedic surgeon. To gain full confidence in the treatment of these injuries, one must have thorough knowledge of the osseous and vascular anatomy, experience with modern methods of fixation, and be prepared to deal with the complications that often occur with talar injuries. Whenever possible reduction of fracture dislocation of talus as emergency remains important. Although, in severe multi system injury patients the surgical management of fracture talus is necessarily delayed. Nonetheless a good result for the talus fracture can still be seen, even when appropriate orthopedic intervention is delayed. 


\section{Materials and Methodology}

Seventeen patients were analysed in our study during the period of august 2014 to September 2016 from Department of Orthopaedics and Traumatology, Thanjavur medical college hospital, Thanjavur, Tamilnadu. All the patients selected for the study were examined according to protocol, associated injuries noted and carried clinical and lab investigations to get fitness for surgery. Consent for surgery was obtained from the patients underwent surgery. Patients were followed till union was achieved clinically with AOFAS (American Orthopaedic Foot and Ankle Society Score) scoring as well as radiologically with $\mathrm{x}$-rays.Inclusion indication of this study for cannulated cancelous screw fixation was simple and compound fracture of talar body and talar neck upto grade II compound injury with good general condition of patients and from 18 to 65 years of age and both sexes. Comorbid conditions not permitting major surgical procedures, compound Gr III A, B, C talar fractures, delayed presentations and poor skin conditions were excluded for this study. The time interval between injury and surgery was 7 to 11 days in our study. The collected data was analysed statistically at the end of the study. The implants and instruments used were cannulated cancelous screws of size $4 \mathrm{~mm}$, cannulated screw system, K-wires, osteotome and mallet.

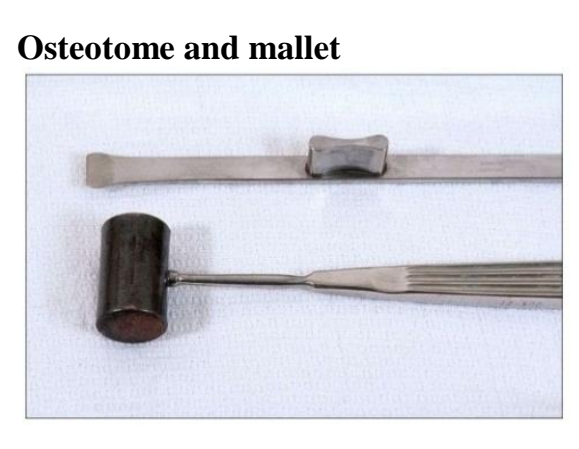

Cannulatedcancelous screw

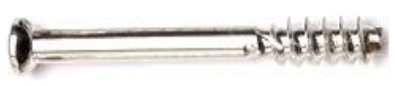

Cannulated screw driver

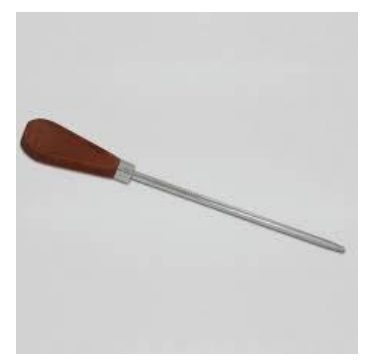

\section{Surgical Procedures}

In eight cases of anteromedial approach the head and neck of the talus was exposed through an incision, $10 \mathrm{~cm}$ long, beginning at the lower third of the leg $1 \mathrm{~cm}$ lateral to the anterior crest of the tibia, running parallel to it and then curved medially to midway between the tip of the medial malleolus and the navicular tubercle. The long saphenous vein was ligated and divided and the saphenous nerve and deltoid artery came in path of the incision was identified and preserved.The medial border of tibialis anterior tendon, along with the long extensor tendons and the neurovascular bundle were mobilised and retracted laterally with the foot dorsiflexed. Malleolarosteotomy facilitate wider exposure if necessary. The fracture and the anteromedial aspect of the neck and body of the talus were exposed. Intact soft tissue was preserved as much as possible around the head and neck of the talus. The fracture was reduced, and the joint was irrigated to remove bone fragments and debris and Internal fixation was done posterior to the articular surface of the head on the medial or lateral aspect of the neck, two or three small Kirschner wires were drilled through the neck and into the body for temporary reduction. Depending on the available space for fixation, a 4.0-mm, 4.5$\mathrm{mm}$, or $6.5-\mathrm{mm}$ partially threaded cannulated screws were used. The osteotomised medial malleolus to improve exposure was reduced and was fixed with a malleolar screw.

In four cases combined anteromedial and posterolateral approach were performed and this approach exposes posterior process and talar body. The interval was made in between the peroneus brevis and the flexor hallucislongus. The sural nerve was protected. The flexor halluces longus was displaced from its groove in the posterior process to facilitate exposure. Internal fixation was performed by placing the guide wire above the lateral projection of the posterior 
process, and was directed toward the lateral talar head under the fluoroscopic guidance to avoid the subtalar joint. In five cases combined anteromedial and anterolateral approach was performed by putting $5-\mathrm{cm}$ incision over the sinus tarsi, extending toward the base of the fourth metatarsal. The dorsal intermediate cutaneous nerve was protectedin this region. After incising the inferior extensor retina culum the extensor digitorum brevis was reflected plantarly to expose the fracture. This approach facilitates visualization of the sinus tarsi, lateral talar neck, and subtalar joint. The artery of the tarsal sinus came in path was mobilised with care during dissection. Postoperative care was given by holding the foot in neutral position in cast, and the ankle was immobilized in cast from below knee to the toes, well moulded into the arch of the foot. After 6 to 8 weeks, depending on radiographic signs of early union, a walking boot was applied and weight bearing was permitted. The cast was removed three months postoperatively with satisfactory union seen.

\section{Results}

The patients were grouped according to age and sex. In this study ten cases (58.8\%) belongs to less than 30 years of age. Majority of them were males 14/17 (82.4\%). Among seventeen patients eight cases anteromedial, four cases combined anteromedial and posterolateral and five cases combined anteromedial and anterolateral approaches underwent for open reduction and internal fixation. All patients were subjected to periodic review by clinical evaluation, immediate post op and after one month,3 months, 6 months, 12 months and 18 months. The follow up was done by the same authors on appropriate dates. The summary of basic clinical variables is presented in Table 1.

Table 1: Basic clinical variables

\begin{tabular}{|l|c|c|}
\hline \multirow{2}{*}{ Age } & & \\
\hline \multirow{2}{*}{ Sex } & Mean $+/-$ SD & Median \\
\cline { 2 - 3 } & $32.9+/-15.27$ & $27(18-63)$ \\
\hline \multirow{2}{*}{ Side Of Injury } & Male & Female \\
\cline { 2 - 3 } & 14 & 3 \\
\cline { 2 - 3 } Mode Of Injury & Right & Left \\
\cline { 2 - 3 } & Fall From Height & RTA \\
\hline \multirow{2}{*}{ Type Of Injury } & 9 & 8 \\
\cline { 2 - 3 } & Simple & Compound \\
\hline \multirow{2}{*}{ AOFAS Score } & 12 & 5 \\
\cline { 2 - 3 } & Preop +/-SD & Postop +/- SD \\
\hline
\end{tabular}

Table 2 Clinical Variables

\begin{tabular}{|l|c|c|c|}
\hline Clinical Variables & & No. of Cases & Percentage \\
\hline \multirow{3}{*}{ Fracture Of Talus } & Head & 2 & 11.8 \\
\cline { 2 - 4 } & Neck & 10 & 58.8 \\
\cline { 2 - 4 } & Body & 5 & 29.4 \\
\hline \multirow{4}{*}{ Associated Fractures } & Malleolar & 4 & 23.6 \\
\cline { 2 - 4 } & Calcanum & 2 & 11.8 \\
\cline { 2 - 4 } & L2 Burst & 1 & 5.9 \\
\cline { 2 - 4 } Approaches & Nil & 10 & 58.8 \\
\hline \multirow{3}{*}{$\begin{array}{c}\text { Anteromedial } \\
\text { Anteromedial \& } \\
\text { Anterolateral }\end{array}$} & 5 & 29.1 \\
\cline { 2 - 4 } & $\begin{array}{c}\text { Anteromedia \& } \\
\text { Anterolateral }\end{array}$ & 4 & 23.6 \\
\cline { 2 - 4 } & & & \\
\hline
\end{tabular}


Table 3: Hawkin's Functional outcome Grading Results

\begin{tabular}{|l|c|c|}
\hline Hawkin's Grading Results & No. of Cases & Percentage \\
\hline Excellent & 5 & 29.41 \\
\hline Good & 6 & 35.29 \\
\hline Fair & 6 & 35.29 \\
\hline Poor & 0 & 0.00 \\
\hline Total & 17 & 100.00 \\
\hline
\end{tabular}

The patients were evaluated preoperatively and post operatively using AOFAS scoring system. The mean AOFAS was 27.1 at preoperative and 58.6 at 3 months postoperative. The improvements were statistically significant $(\mathrm{P}<0.001)$ from preoperative score. Functional outcome was assessed by Hawkin's grading and found to be excellent outcome in 5 cases, good in 6 cases, fair in 6 cases and nil poor outcome. Minor complications like wound infection and screw prominence were encountered in a case and was managed with IV antibiotics and screw removal. Subtalar arthrodesis were done in two cases who developed a vascular necrosis and subtalar arthritis each.

\section{Case 1}

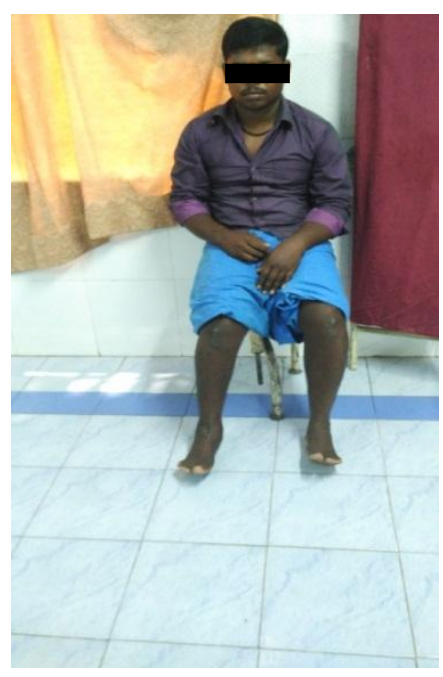

Clinical Picture

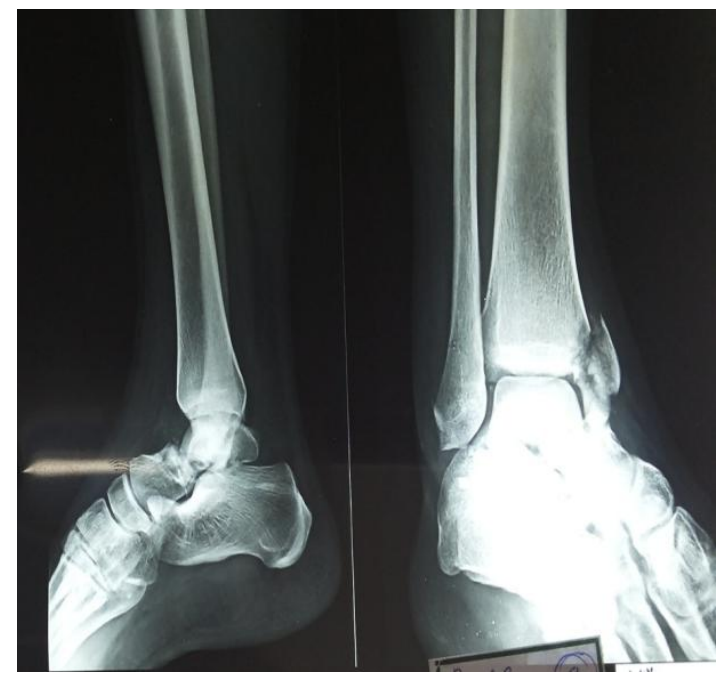

Preoperative X-Rays

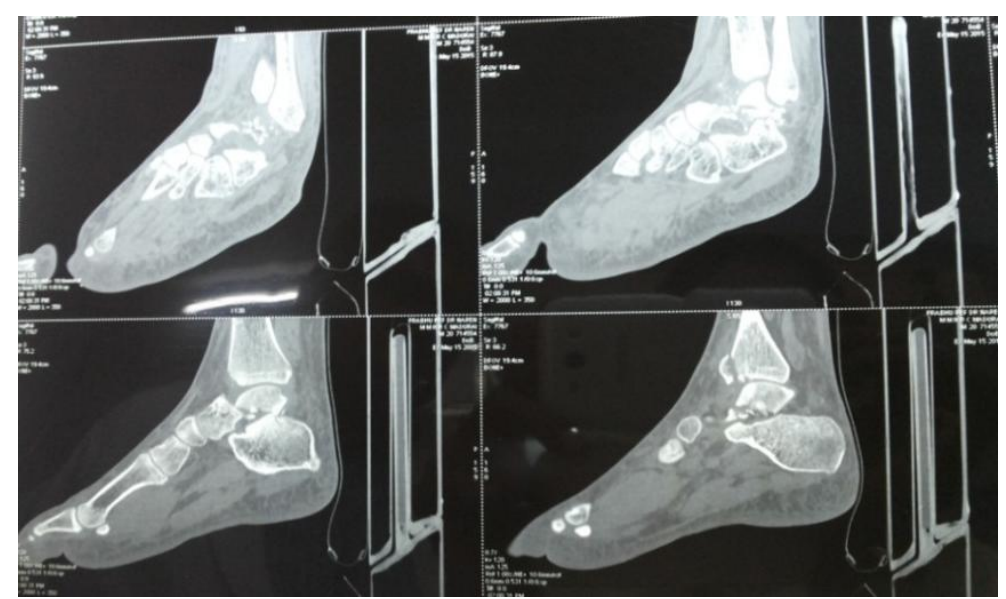

Preoperative CT scan 


\section{JMSCR Vol||06||Issue||05||Page 169-177||May}

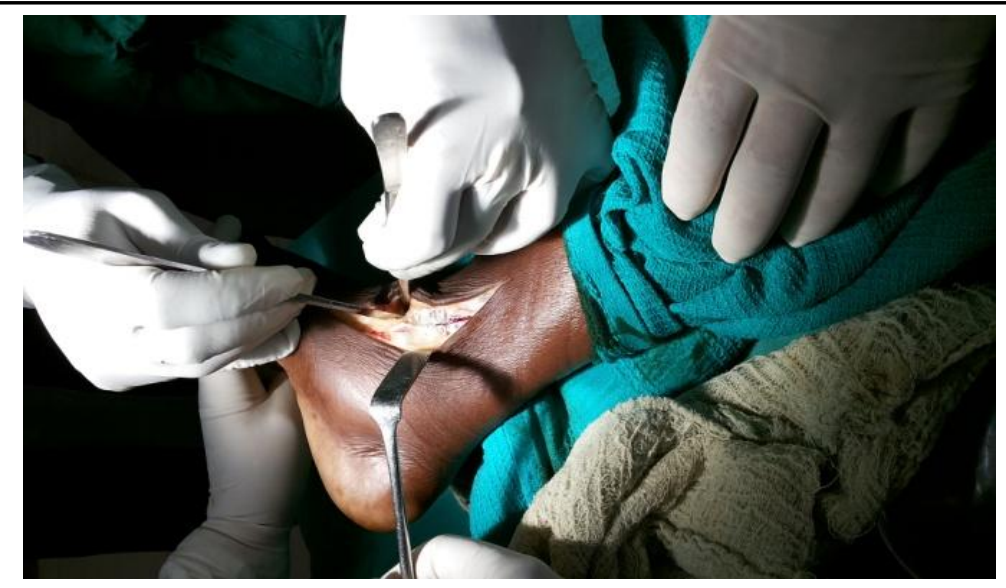

Intraoperative approach

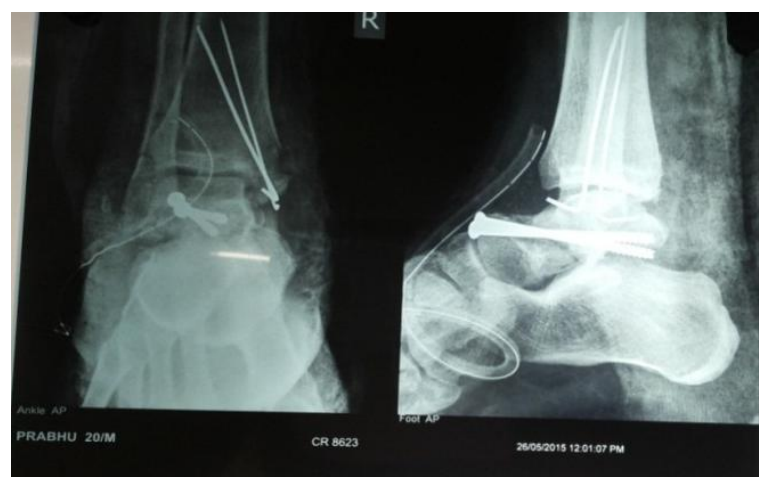

Postoperative X-RAY

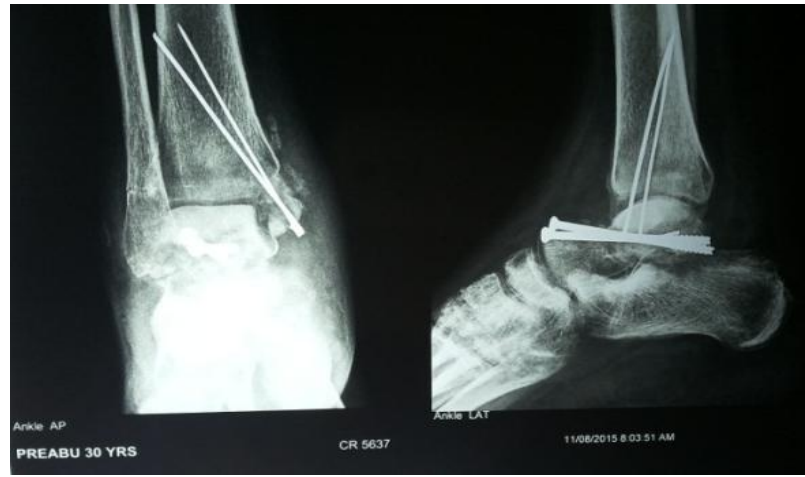

3 Month Follow up

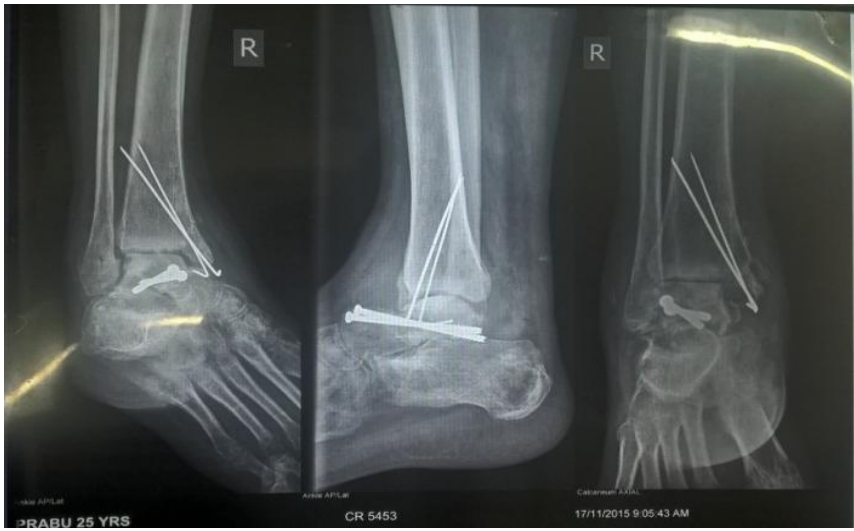

6 Months Follow up X-Ray

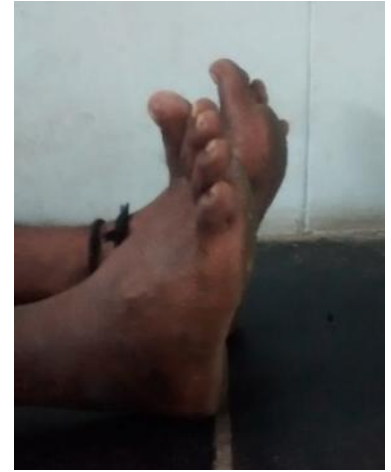

Dorsiflexion (0-10 deg)

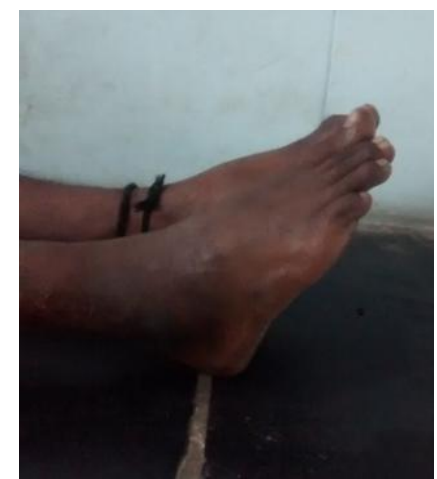

Plantar flexion (0-30 deg)

(minimal post op stiffness present) 


\section{JMSCR Vol||06||Issue||05||Page 169-177||May}

\section{Case 2}

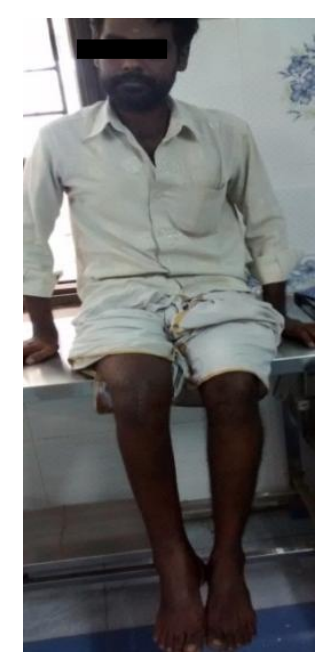

Clinical picture

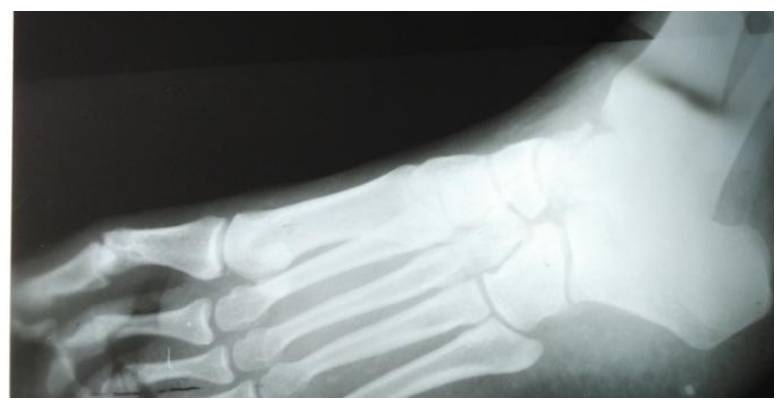

Preoperative X-ray

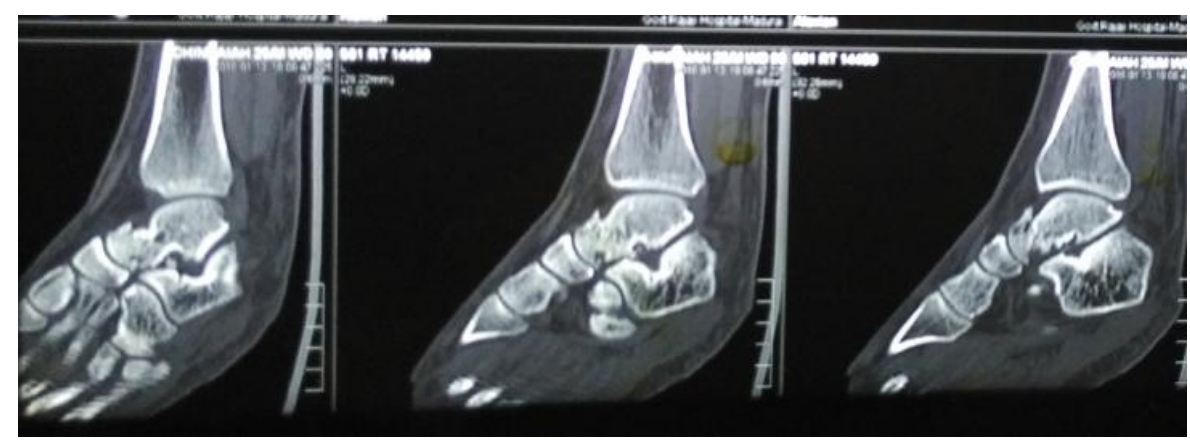

Preoperative CT scan

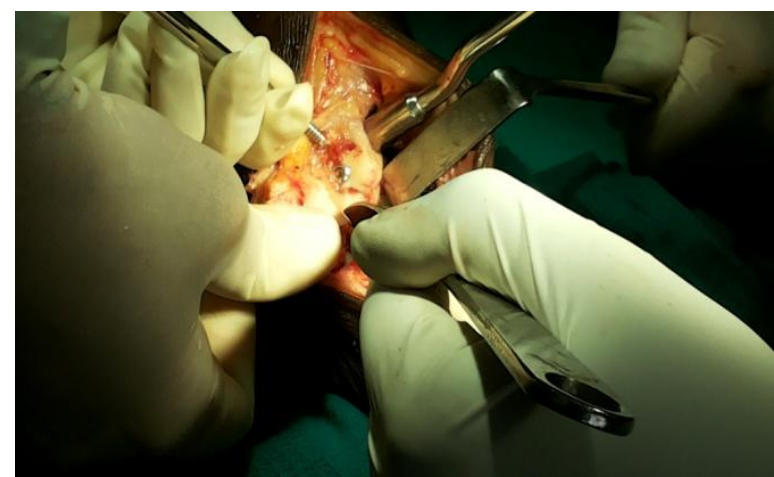

Intraoperative approach

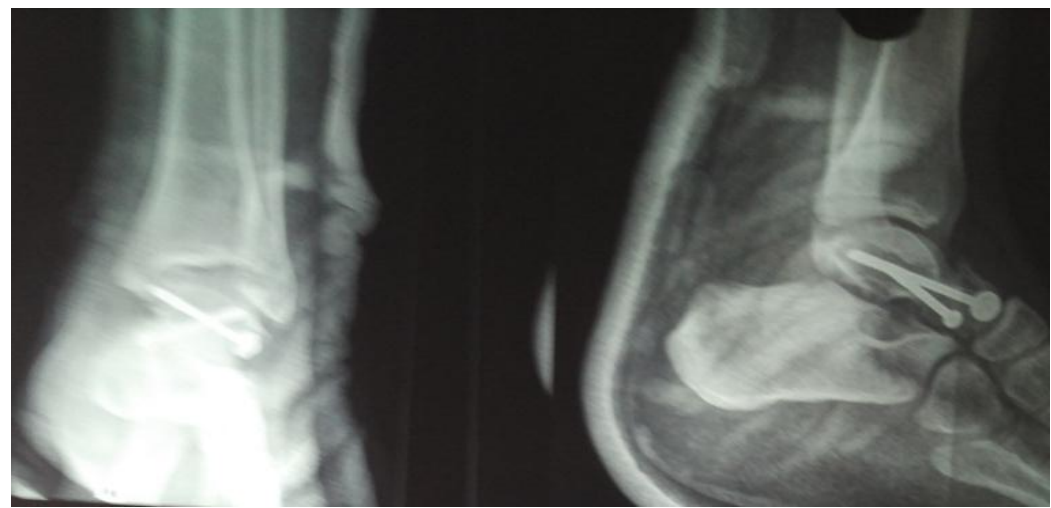

Postoperative X-ray 


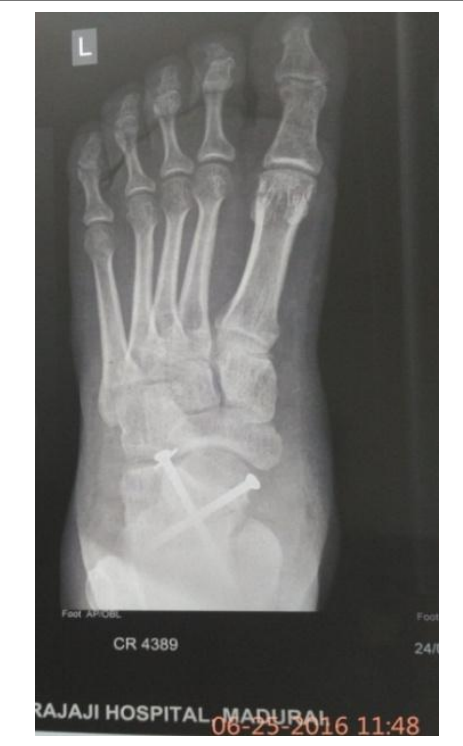

6 Months Follow up X-ray

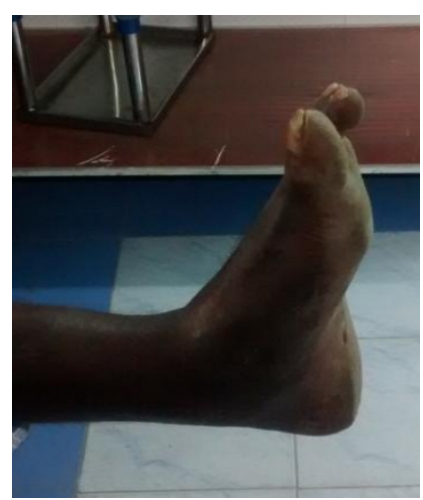

Dorsiflexion (0-10deg)

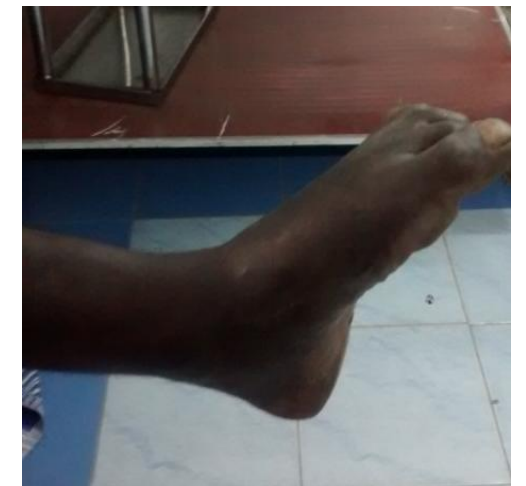

Plantar Flexion (0-40deg)

\section{Discussion}

Talar fractures are second in frequency among all tarsal fractures. Two percent of all lower extremity injuries and $5 \%$ to $7 \%$ of foot injuries involve fractures of the talus. Neck of talus fractures are commonly the result of a hyperdorsiflexion-type injury of foot, usually associated with talar neck fracture. The mechanism of progressive hyperdorsiflexion forces was described by Penny and Davis ${ }^{1}$, also Anderson described the aviators' astragalus. Pilots sustained a hyperdorsiflexion force during the impact of sole on the rudder bar such that neck of talus fractures were relatively common. Coltart $^{2}$ described talar fracture in flying accidents. Nowadays accidents in motor vehicle and fall from height results serious talar fractures. Lowenergy injuries can also result in talus fractures. Fractures of the lateral and posteromedial processes of the talus can result from inversion and eversion mechanisms such as are commonly seen in sports injuries and also often results subtalar dislocations and can vary with respect to severity of injury mechanism. On occasion, talus and neuropathic joints have association and its management is difficult. Typically, the midfoot progressively dorsiflexes relative to the body of the talus, resulting in significant loss of ankle motion and deformity of the hindfoot. Often fractures of the talar neck and body are in alliance with one another. In this case the proposed mechanism of injury relates more to axial load than to the specific position of the foot. However, dorsiflexion is usually an associated mechanism. Talus fractures are frequently associated with tibial plafond and malleolar fractures. The incidence of associated malleolar injury ranged from $19 \%$ to $28 \%$ in prior studies. Fractures of both bone leg can be addressed along with the talus fracture and may even afford a means of exposure of the talar body through the malleolar injury. Ten percent of calcaneal fractures has been conjoined with talar neck fractures, also found together with tibiofibular diastasis.

Anteroposterior (AP), mortise, and lateral images of the ankle, in addition AP, lateral, and oblique views of the foot are obtained. In Canale view the ankle was kept in maximum equinus with the foot 15 degrees pronated and placed on a cassette and the $\mathrm{x}$-ray beam directed 15 degrees cephalad from vertical for perfect view of talar neck, described by Canale and Kelly ${ }^{3}$.Computed tomography (CT) is useful to assess displacement, articular extension and fracture patterns. Technetium bone scans or magnetic resonance imaging (MRI) may be useful in evaluating possible occult talar fractures. Immediate closed reduction is indicated, with emergency open reduction and internal fixation (ORIF) for all open or irreducible fractures. In undisplaced fractures the patients 
were put on short leg cast after anatomical reduction confirmed using CT scan .In open reduction all major fragments were salvaged and primary arthrodesis was avoided. In our study we used eight cases anteromedial approach, four cases combined anteromedial and posterolateral and five cases combined anteromedial and anterolateral approaches for internal fixation. Two or three K-wires were drilled through the neck and into the body to maintain the reduction using image intensifier guidance and fixed with partially threaded cannulated cancelous screws and countersink the screw head. Postoperatively below knee cast applied with ankle in neutral position continued for 6 to 8 weeks followed by ankle mobilising exercises. As soon as the wound healed, a below knee cast was applied and full weight bearing was not permitted till union was visualised radiologically. Fournier et l $^{4}$ reported dual approach exposed medial and lateral faces of talar neck and facilitate better reduction also minimal interferences in blood supply to talar fragments. Paul $T$ et $a l^{5}$ reported medial and anterolateral exposure gives an accurate assessment of reduction and good fixation of talar neck and a posterolateral approach is used for placement of cannulated screws for final fracture fixation described by Trillat et al, also allows safe access to the entire posterior talar process. Posterior-to-anterior screw placement gives superior mechanical strength. Wito Schulze et $a l^{6}$ preferred the antero-medial approach for talat neck fracture fixation. Xavier et $a l^{7}$ reported risk of skin necrosis, infection (10-20\% depending on authors) and increased the duration of surgery occurs in dual approach even though it permits better visualisation of the talus and no dual approach was used and fractures were managed through a single approach which would explain the low rate of infection in his study. Delayed surgical fixation was not found to affect the outcome, union, or prevalence of osteonecrosis but complication like posttraumatic arthritis is increasingly common. Posttraumatic arthritis and chronic pain are anticipated outcomes even after anatomic reduction and stable fixation of displaced talar fractures especially compound and need patient counselled ${ }^{8}$. By restoring a nearnormal range of motion and function to a fit young male, the severely limiting effects of arthrodesis were avoided or at least delayed. Failed open reduction and internal fixation cases be reserved for primary arthrodesis which is only a justifiable alternative 9 . Functional outcome varied and was most dependent upon the development of complications. Subtalar arthritis or misalignment following neck of talus fracture results in increasing secondary reconstructive surgery ${ }^{10}$.

\section{Conclusion}

This study analyse various approaches performed in talar fracture to visualise talar neck and talar body in open reduction and internal fixation and its outcome. Among all the approaches discussed above, combined anteromedial and antero lateral approach helped better visualization of talar neck and talar body for good fixation and excellent outcome. The screw can be fixed either anterior to posterior direction or from posterior to anterior direction however screws administered posterior to anterior are biomechanically stronger. Open reduction and internal fixation with screws in fractures of talus facilitates early patient ambulation and helped to achieve stable, pain free subtalar and ankle joints, preventing osteonecrosis of talus and subtalar and ankle joint arthritis. Hawkin's grading shows significant improvement during follow up.

\section{References}

1. Sanders D.W. Talus fractures. In: Rockwood C.A., Green D.P., editors. Fractures in adults. Lippincott Williams \& Wilkins; Piladelphia: 2010. pp. 2022-2063.

2. Coltart, W. D. (1952) Aviatorsastragalus. .I. Bone Jt Surg. 34-B, 545-566.

3. Canale S.T., Kelly F.B., Jr. Fractures of the neck of the talus long-term evaluation of 
seventy-one cases. J Bone Joint Surg Am. 1978;60(2): 143-156.

4. Fournier a, N. Barbaa, V. Steiger b, A. Lourdais i, J.-M. Frinb, T. Williams cV. Falaise d, V. Pineaue, E. Salle de Choue, T. Noailles f, G. Carvalhanag F. Ruhlmann h, D. Hutena,* Total talar fracture - Long-term results of internalfixation of talar fractures. A multicentric study of 114 cases Orthopaedics \& Traumatology: Surgery \& Research (2012) 98, S48-S55

5. Paul T. Fortin, MD, and Jeffrey E. Balazsy, MD Talus Fractures: Evaluation and Treatment J Am Acad Orthop Surg 2001;9: 114-127

6. Wito Schulze, Jens Richter, Otto Russe, Patrick Ingelfinger \& Gert Muhr.(2002) Surgical treatment of talus fractures, Acta Orthopaedica Scandinavica, 73:3, 344-351,

7. Xavier Ohl, corresponding author Alain Harisboure, Xavier Hemery, and Emile Dehoux Long-term follow-up after surgical treatment of talar fractures Twenty cases with an average follow-up of 7.5 years Internation Orthopaedics 2011 Jan; 35(1): 93-99.

8. Lindvall E, Haidukewych G, Di Pasquale T, Herscovici D Jr, Sanders R: Open reduction and stable fixation of isolated, displaced talar neck and body fractures. J Bone Joint Surg Am 2004, 86:2229-2234

9. J Isaacs, B Courtenay, A Cooke, M Gupta Open reduction and internal fixation for concomitant talar neck, talar body, and medial malleolar fractures: a case report. Journal of Orthopaedic Surgery 2009;17 (1): 112-5

10. Sanders, David W. MD, MSc, FRCS(C), Busam, Matthew MD, Hattwick, Emily MD, Edwards, John R. MD, Mc Andrew, Mark P. MD, Johnson, Kenneth D. MD. Functional Outcomes Following Displaced Talar Neck Fractures Journal of Orthopaedic Trauma: May-June 2004 - Volume 18 - Issue 5 - p 265-270. 